ANUARIO DE ESTUDIOS MEDIEVALES

50/1, enero-junio de 2020, pp. 211-230

ISSN 0066-5061

https://doi.org/10.3989/aem.2020.50.1.08

\title{
DEL ROJO AL NEGRO: \\ INDICIOS DE UN CAMBIO DE MENTALIDAD EN FUENTES MEDIEVALES HISPANAS DEL SIGLO X ${ }^{1}$
}

\author{
FROM RED TO BLACK: \\ EVIDENCE FOR A CHANGE IN MENTALITY \\ IN TENTH-CENTURY HISPANIC MEDIEVAL SOURCES
}

\author{
PABLO MARTÍN PRIETO \\ Universidad Complutense de Madrid \\ https://orcid.org/0000-0002-1451-2328
}

\begin{abstract}
Resumen: En este artículo se abordan algunos indicios de cambio de mentalidad acerca de la percepción y valor simbólico de los colores básicos en algunas fuentes medievales de la España cristiana. Cierta interesante diferencia de transmisión que afecta a una cita bíblica en concreto -Is 1, 18- hallada tanto en el Antifonario visigótico de la catedral de León como en un diploma real de Ramiro III, apunta a dicho cambio de mentalidad referido a la concepción del negro, y no ya del rojo, como el nuevo color en ser considerado como esencialmente opuesto al blanco. Este cambio se examina asimismo a la luz de algunos ejemplos tomados del acervo de la literatura cristiana occidental.
\end{abstract}

Palabras clave: historia de las mentalidades; rojo; negro; blanco; León; Isaías 1, 18; Ramiro III.

Abstract: This paper considers some evidence for a change in mentality concerning the perception and symbolic values of the basic colours in certain Christian sources from medieval Spain. A number of interesting differences in the transmission of a specific Biblical quotation-Is 1:18- observed both in the Visigothic Antiphonary of the León Cathedral and in a charter of King Ramiro III point to this change in mentality, underlining the concept of black, and no longer red, as the new colour considered as essentially opposite to white. This change is further examined in the light of some examples from Western Christian literature.

Keywords: history of mentalities; red; black; white; León; Isaiah 1:18; Ramiro III.

\section{SUMARIO}

1. Introducción.- 2. Los colores de Is. 1, 18.- 3. La transmisión de Is 1, 18.- 4. La excepción: negro vs. blanco en Is. 1, 18.- 5. Blanco, negro y rojo: sus valores y términos de oposición.- 6. Blanco, negro y rojo: ejemplos en la mentalidad y la literatura.7. Conclusión.- 8. Bibliografía citada.

\footnotetext{
${ }^{1}$ Abreviaturas utilizadas: Apoc $=$ Apocalipsis; AT $=$ Antiguo Testamento; $\mathrm{BN}=$ Biblioteca Nacional, Madrid; Dan = Daniel; Dt = Deuteronomio; Ecl = Eclesiastés; Éx = Éxodo; $\mathrm{GE}=$ General Estoria; Gen = Génesis; Is = Isaías; Lc = Lucas; Lv = Levítico; LXX = Setenta; Mc = Marcos; Mt = Mateo; Nah = Nahún; Núm = Números; RAH = Real Academia de la Historia, Madrid; Sal = Salmos; VL = Vetus Latina; Zac $=$ Zacarías .

Citation / Cómo citar este artículo: Martín Prieto, Pablo (2020), Del rojo al negro: indicios de un cambio de mentalidad en fuentes medievales hispanas del siglo X, "Anuario de Estudios Medievales" 50/1, pp. 211-230. https://doi.org/10.3989/ aem.2020.50.1.08

Copyright: (C) 2020 CSIC. Este es un artículo de acceso abierto distribuido bajo los términos de la licencia de uso y distribución Creative Commons Reconocimiento 4.0 Internacional (CC BY 4.0).
} 


\section{INTRODUCCIÓN}

Entre los cambios que más difícil resulta percibir, dentro de la evolución de las sociedades humanas, pueden tal vez contarse los que tienen que ver con los fenómenos relacionados con lo que se ha venido en llamar mentalidad. Colindando con los métodos y enfoques de la Historia social y cultural, la Historia de las mentalidades ha venido rindiendo apreciables esfuerzos y consolidando resultados que contribuyen a definir las líneas generales y modalidades de evolución, en la larga duración, de las cosmovisiones (Weltanschauungen) o concepciones generales sobre la realidad y la vida, en el contexto de las diversas sociedades.

En este trabajo pretendemos realizar una mínima y modesta contribución a la microhistoria de las mentalidades, relativa a la percepción y representación de algunos de los colores básicos y sus relaciones, al hilo de su posible evolución en el seno de la cultura medieval occidental. Sobre la base de unos reveladores testimonios localizados en un importante códice litúrgico hispano y en un diploma regio leonés, ambos probablemente coetáneos y datables en la segunda mitad del siglo $X$, se trata aquí de postular la posibilidad de apoyar teorías de validez general para el conjunto del Occidente medieval, que apuntan al cambio de mentalidad subyacente a la substitución generalizada del rojo por el negro como color opuesto por excelencia al blanco. Se trata de un hecho que es posible y conveniente percibir imbricado en el juego de todas sus complejas implicaciones, y propiamente polisémico en el contexto de la cultura de la época; nuestra contribución sugiere la posibilidad de valorar el ejemplo estudiado como indicio de anticipación en suelo hispano del cambio de mentalidad en cuestión. No se afirma con ello que en la Península Ibérica necesariamente haya comenzado dicha transformación de mentalidad, o que sea aquí perceptible con anticipación, por comparación con el conjunto del Occidente medieval; sino que únicamente se procura poner sobre el tapete una instancia que estimamos relevante para contribuir a precisar el proceso gradual de substitución de un paradigma imaginario por otro, con su cronología aproximada.

Tomando como punto de partida una cita concreta del libro del profeta Isaías, procederemos primeramente a trazar el panorama general de su significación y transmisión en el seno de la cultura cristiana medieval, y la apreciación de conjunto sobre la historia de su traducción e influencia sobre dicha cultura nos servirá como punto de apoyo para percibir la diferencia clave que se opera cuando en ciertos testimonios del siglo $\mathrm{X}$ hispano se introduce una expresión que viene a alterar y contradecir radicalmente la valoración o significación hasta entonces unánimemente admitida en Occidente al hilo de la transmisión e interpretación del mencionado pasaje bíblico. El estudio de 
esta alternativa abre la posibilidad de relacionar los mencionados testimonios hispanos del siglo $\mathrm{X}$ con la corriente que, documentada hasta ahora como posterior, explica la transformación de la mentalidad occidental en torno a la percepción y valoración del juego de oposición entre estos colores básicos; y de ahí la posibilidad de derivar las conclusiones de nuestro estudio.

\section{LOS COLORES DE IS 1,18}

El libro de Isaías ocupa una posición muy eminente entre los de la Biblia por sus propias características y también como uno de los libros del Antiguo Testamento más citados en el Nuevo. Su influencia en la literatura cristiana medieval necesariamente ha de considerarse inmensa, debido a su gran presencia en los textos de la liturgia (únicamente superada, en términos estadísticos, por la utilización que en ésta se hace de los Salmos) ${ }^{2}$.

Por lo que se refiere a Is 1,18 , ya la misma inserción del pasaje en su contexto plantea problemas a los especialistas, según la unidad o perícopa de la que crean que forma parte. Por una parte, se subraya que no se trata de un texto concebido como independiente, sino conectado con los versículos anteriores en temas y redacción ${ }^{3}$ (los tonos rojizos asociados al pecado se corresponden con la sangre de Is 1, 15; el paso del rojo al blanco, con la purificación del mal de que se trata en Is 1, 16; incluso la referencia a la lana remite a las ovejas de Is 1, 11; también el empleo de la segunda persona gramatical continúa el de Is $1,10-17^{4}$ ). Sin embargo, también se ha de notar que con Is 1,18 se abre un pasaje exhortatorio que guarda unidad de sentido con los versículos inmediatamente posteriores: en continuidad, Is 1, 18-20 constituye una cita de la palabra de Dios en boca del profeta ${ }^{5}$.

La expresión inicial de Is 1,18 es un término legal según los convencionalismos del género forense o procesal: una fórmula de litigación como aquellas con las que típicamente se llevaba e iniciaba un asunto ante un tribunal ("litiguemos"), lo que remite al contexto de un proceso en que Dios figura como acusador frente al pueblo de Israel, si bien la fórmula se puede interpretar asimismo como coloquial, sin "frío tono legalista", sino como invitación a debatir y acordar diferencias (“discutamos").

\footnotetext{
${ }^{2}$ Sagrada Biblia. Versión oficial de la Conferencia Episcopal Española 2011, p. 911; Asurmendi 1981; Blenkinsopp 2015; Tábet, et al. 2008, pp. 111-115, 139-164.

${ }^{3}$ Carr 1996, p. 199.

${ }^{4}$ Sweeney 1996, p. 82.

${ }^{5}$ Kutsch 1982, p. 23.

${ }^{6}$ Goldingay 1981, p. 138; Kutsch 1982, pp. 29-30; Willis 1983, pp. 38-40.
} 
A continuación, se halla el pasaje en el que se relaciona el pecado con el color rojo y su negación con el blanco; la interpretación tradicional desde la versión de los Setenta ("blanquearé": $\lambda \varepsilon v \varkappa \alpha \varkappa \hat{\omega}^{7}$ ) y hasta Lutero (pasando por la Vulgata, los rabinos antiguos y los Padres de la Iglesia) tiene que ver con la gracia, con una oferta incondicional de perdón por parte de Dios, pero esto choca con una formidable serie de objeciones $^{8}$ que la crítica se impone examinar. En Is 6, 7 se habla del perdón de Dios que limpia al pecador arrepentido, pero en Is 1, 18-20 la referencia al arrepentimiento por el pecado sólo viene después de la promesa de perdón, como si éste fuera incondicional, lo que parece casar mal con el mensaje de Isaías, construido sobre el contraste entre dos vías o caminos: el de la obediencia a Dios (la vida) y el de la desobediencia (la muerte), conforme a una oposición ya presente en Dt 30,15; como se ha observado, si Dios lavara el rojo del pecado anulando éste, ya no cabría distinguir entre las consecuencias de la obediencia y las de la desobediencia, lo que haría innecesaria la siguiente exhortación del profeta a elegir el buen camino (ya que ambos conducirían a idéntico resultado) ${ }^{9}$.

El paralelo veterotestamentario más importante a Is 1, 18 es Sal 51, 9, donde se habla también de purificación mediante el hisopo y el lavatorio, con resultado de limpieza y blancura nívea ${ }^{10}$; sin embargo, como se ha señalado, la diferencia radica en que en el salmo lo que se blanquea y queda limpio es el pecador, no los pecados como en Isaías, donde se habla de la mutación de color de éstos ${ }^{11}$. Puesto que es imposible que un pecado sea un no-pecado (tanto como es imposible que el color rojo sea blanco), se ha propuesto la interpretación alternativa de Is 1,18 en términos de interrogación retórica, ironía y refutación ${ }^{12}$, compatible con los términos generales de una exhortación a la conversión que no niega la posibilidad del perdón divino ${ }^{13}$.

Con todo, para los propósitos de nuestra investigación lo más relevante del citado pasaje de Isaías es que presenta la oposición entre rojo y blanco, para representar el pecado y su negación o ausencia, respectivamente. Literalmente, se habla en Is 1, 18 de hacer que "pecados rojos" se vuelvan "(pecados) blancos", pero no cabe entender como operativo en la mente del autor sagrado el concepto "pecados blancos", sino en metáfora la oposición o el paso del

\footnotetext{
${ }^{7}$ Troxel 2008.

${ }^{8}$ Goldingay 1981, p. 137.

${ }^{9}$ Kutsch 1982,pp. 28-29.

${ }^{10}$ Vulgata: "Asperges me hyssopo, et mundabor; lauabis me, et super niuem dealbabor".

${ }^{11}$ Kutsch 1982, p. 26. p. 291.

${ }^{12}$ Goldingay 1981, pp. 138-139; Kutsch 1982, p. 27; Willis 1983,pp. 40-42; Melugin 1996,

${ }^{13}$ Otros pasajes de Isaías donde se insta a la conversión con la promesa de perdón divino: 28 , 16-17; 30, 19-22; 31 , 4-8; 38, 17; 55, 6-7; 57, 14-19; 58, 6-12; Willis 1983, p. 46.
} 
color rojo al blanco como imagen del paso de "pecado" a "no-pecado"14. Ambos colores juegan un papel determinante en el contexto de las ceremonias de purificación del AT (de los sacerdotes, de personas contaminadas por contacto con muertos o leprosos, o de las casas en que han morado estos últimos ${ }^{15}$ ): en ellas, el oficiante rociaba a aquel o aquello que debía ser purificado con una mezcla de agua y sangre. El tránsito del rojo al blanco se expresa en Isaías en términos no físicos, sino espirituales, como algo que debe hacerse presente en la conciencia del pecador, por contrición ${ }^{16}$. Pero, desde un punto de vista antropológico -además de contar con las evidentes connotaciones que asocian el rojo a la sangre y su derramamiento (presente en graves delitos) y el blanco a la limpieza material y su correlato la pureza espiritual-, la oposición entre el pecado y el no-pecado ilumina la consideración que en el mundo mental del AT se tenía del rojo (pecado) como un color (incluso el color por excelencia y preferido entre los antiguos hebreos ${ }^{17}$ ) y del blanco (no-pecado) como un "nocolor", esto es, como la falta o ausencia de color. En estos términos, el blanco vendría a ser el opuesto por negación o ausencia de cualquier color, pero sobre todo, del color por antonomasia: el rojo, color principal entre los hebreos.

\section{LA TRANSMISIÓN DE IS 1,18}

Parece interesante en este punto considerar algunos hitos clave en la transmisión del texto referido del libro de Isaías a la posteridad cristiana medieval, y al hilo de dicha comprobación anotar de qué manera, y con qué términos, irán apareciendo las citadas referencias de color.

En primer lugar, por su antigüedad y repercusión, cabe estudiar los textos de la versión griega de los Setenta, las versiones latinas agrupadas bajo la rúbrica de Vetus Latina y la Vulgata. En los Setenta, se trata de pecados

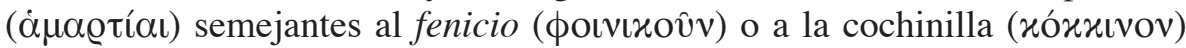
y de que sean blanqueados para que luzcan como la nieve ( $\chi$ ıóv $\alpha$ ) y la lana ('̌oıov), respectivamente ${ }^{18}$ : el color rojo se expresa aquí por asociación con dos términos utilizados para designar colorante de uso corriente en la fabricación textil: (tinte) fenicio y cochinilla; la referencia al blanco no aparece sino implícita en la comparación con la nieve y la lana, pero explícita en el verbo

\footnotetext{
${ }^{14}$ Kutsch 1982, pp. 25-26.

${ }^{15}$ Éx 29, 20-21; Lv 8, 30; 14, 1-9; 14, 48-53; Núm 19, 16-19.

${ }^{16}$ Willis 1983 , p. 43.

${ }^{17}$ Tatarkiewicz 1989, p. 12; Vaux 1976, p. 583.

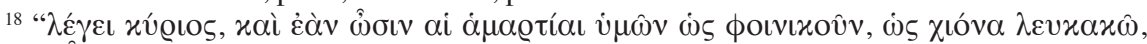

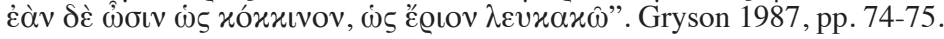


$(\lambda \varepsilon v \varkappa \alpha \varkappa \hat{\omega})$. En las formas antiguas de la Vetus Latina (esto es, las no adscritas ni al tipo africano ni al europeo, principalmente en los tratados de Tertuliano y otros padres apostólicos) se alude a delitos (delicta) como (tinte) rojo (roseum) y cochinilla (coccinum) $)^{19}$; en las formas de los tipos africano y europeo de la VL, se habla respectivamente de pecados (peccata) y delitos (delicta) semejantes al (tinte) fenicio (Phoenicium) y a la cochinilla (coccum) $)^{20}$; en la Vulgata, de pecados (peccata) comparados a la cochinilla (coccinum) y denotados rojos (rubra) como el bermellón (uermiculus: otro nombre para la cochinilla $)^{21}$. En todas las formas de la VL y en la Vulgata, los segundos términos de la sugerida transformación son invariablemente la nieve y la lana (con la ocasional precisión de que esta última sea blanca o limpia). Este rápido recuento se puede visualizar en la siguiente tabla:

\begin{tabular}{|c|c|c|c|}
\hline VERSIÓN & OBJETO & $\begin{array}{l}\text { PRIMEROS TÉRMINOS } \\
\text { (ROJO) }\end{array}$ & $\begin{array}{l}\text { SEGUNDOS TÉRMINOS } \\
\text { (BLANCO) }\end{array}$ \\
\hline LXX & pecados ( $\dot{\alpha} \mu \alpha \varrho \tau i ́ \alpha \iota)$ & 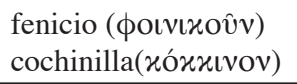 & $\begin{array}{l}\text { nieve ( }(\chi\llcorner o ́ v \alpha) \\
\text { lana ('̌@ıเov) }\end{array}$ \\
\hline VL - antiqua & delicta & $\begin{array}{l}\text { roseum } \\
\text { coccinum }\end{array}$ & $\begin{array}{l}\text { niuem } \\
\text { lanam }\end{array}$ \\
\hline $\mathrm{VL}$ - africana & peccata & $\begin{array}{l}\text { Phoenicium } \\
\text { coccum }\end{array}$ & $\begin{array}{l}\text { niuem } \\
\text { lanam }\end{array}$ \\
\hline VL - europea & delicta & $\begin{array}{l}\text { Phoenicium } \\
\text { coccum }\end{array}$ & $\begin{array}{l}\text { niuem } \\
\text { lanam candidam / albam }\end{array}$ \\
\hline Vulgata & peccata & $\begin{array}{l}\text { coccinum } \\
\text { rubra- - uermiculus }\end{array}$ & $\begin{array}{l}\text { nix } \\
\text { lana (alba / munda) }\end{array}$ \\
\hline
\end{tabular}

De donde resulta que, como puede apreciarse, únicamente la Vulgata da expresamente un término de color ( $r u b r a)$ para el rojo, siendo así que este tono viene aludido por los distintos nombres de la púrpura o cochinilla ${ }^{22}$, el tinte rojo típicamente asociado a los fenicios y que da nombre a este pueblo antiguo $^{23}$; y en algunas lecturas de la Vetus Latina europea y de la Vulgata se

19 "dicit Dominus: et si fuerint delicta vestra tamquam roseum/russeum/rufum, velut nivem exalbabo; et si tamquam coccinum, velut lanam exalbabo": Gryson 1987, pp. 74-75.

20 "dicit Dominus: et si fuerint peccata vestra ut/quasi/velut Foenicium, ut nivem exalbabo/ inalbabo; et si fuerint quasi coccum, ut lanam inalbabo/dealbabo" (afr.); "dicit Dominus: et si fuerint delicta vestra sicut Foenicium, ut/tamquam/sicut nivem dealbabo; si autem/vero fuerint ut/sicut coccum, ut/tamquam/sicut lanam candidam/albam efficiam/faciam" (eur.): Gryson 1987, pp. 74-75.

21 "dicit Dominus: si fuerint peccata vestra ut coccinum, quasi nix dealbabuntur/dealbantur; et si fuerint rubra quasi vermiculus, velut lana (alba/munda) erunt": Gryson 1987, pp. 74-75.

${ }^{22}$ Phipps 2010.

${ }^{23}$ Plinio, Historia natural, 9, 125-140. 
añade a la lana adjetivos de color (candida, alba). Así, el contraste de color entre el rojo y el blanco queda claro y se visualiza por los términos alusivos al colorante textil.

También resulta interesante evocar aquí algunos ejemplos de romanceamiento castellano del pasaje en cuestión. En la Biblia castellana prealfonsí de $c a$. 1250, representada por los códices I.i.8 y I.i.6 de la Biblioteca del Real Monasterio de El Escorial, el texto de la Vulgata se vierte al romance dando panno uermeio por coccinum y gusaniello por vermiculus; se traduce el término de color rubra por uermeios y se añade alba a lana ${ }^{24}$. El mismo reparto: paños bemejos y gusano, se observa asimismo en manuscritos tardíos relacionados con el horizonte de las versiones castellanas del texto hebreo, como en el manuscrito 87 de la Real Academia de la Historia, de $c a$. 1450-1470 En cambio, los dos términos de colorante textil se reducen a uno solo en la traducción castellana incorporada a la General Estoria de Alfonso X: yerua coçano o $\operatorname{coco}^{26}$. Algunas traducciones castellanas del hebreo, ya del siglo XV, introducen nuevos términos para referirse a los colorantes: así, por ejemplo, grana en el manuscrito escurialense I.i.4, de $c a .1400-1430^{27}$; escarlata en el también escurialense I.i.3, de ca. 1425-145028; cremesi y grana en el manuscrito 10288 de la Biblioteca Nacional, de la primera mitad del siglo XV (posiblemente hecho para el marqués de Santillana) ${ }^{29}$; y en la famosa Biblia de Alba mosén Arragel da grana y lana blanca ${ }^{30}$. En todas estas traducciones del hebreo citadas aparece el verbo emblanquecer, y en la mayoría, también

\footnotetext{
24 "Si fueren uuestros pecados cuemo panno uermeio, assi como nief seran enblanquecidos; e si fueren uermeios como gusaniello, atales seran como lana alba": El Escorial, mss. I.i.8 (E8) y I.i.6 (E6): Enrique-Arias.

25 "Sy fueren vuestros pecados commo paños bermejos, commo la nieue sse enblanquesçeran; et ssy fueren bermejos commo el gusano, como lana sseran": Real Academia de la Historia, ms. 87: Enrique-Arias.

26 "Sy fueren los vuestros pecados como la yerua coçano o coco, que es eso mesmo, asy seran enblanquidos como nieue; y sy fueren bermejos como [bermejeub], que es otrosy coçano o coco, y entiendese por y los grandes pecados, como lana seran blancos": Biblioteca Pública de Évora, ms. CXXV/2-3 (códice R de la GE): Enrique-Arias.

27 "Avn que sean vuestros pecados commo la grana, commo la nieue enblanquesçeran; et sy fueren bermejos commo el gusano, commo la lana blanca seran" El Escorial, ms. I.i.4 (E4): Enrique-Arias.

28 "Sy fueren vuestros pecados commo bermejos [sic] commo nieue enblanquesçeran; et sy se enbermejeçieren commo escarlata, commo lana seran": El Escorial, ms. I.i.3 (E3): EnriqueArias.

29 "Si fueren vuestros peccados asy commo cremesi, commo la nieue se enblanquesçeran; et si se enbermegeçieren commo la grana, como la lana seran": Biblioteca Nacional (Madrid), ms. 10288: Enrique-Arias.

30 "Sy fueren los vuestros pecados bermeios, asy commo la nieue se enblanqueçeran; et sy se enbermejeçieren commo la grana, asy commo la lana blanca seran": Palacio de Liria (Madrid), Biblia de Alba: Enrique-Arias.
} 
el verbo embermejecer $^{31}$. Nuevamente puede observarse la claridad con que queda establecida la oposición entre el rojo y el blanco en la tradición de las biblias castellanas bajomedievales.

\begin{tabular}{|l|l|l|}
\hline BIBLIA & PRIMEROS TÉRMINOS (ROJO) & SEGUNDOS TÉRMINOS (BLANCO) \\
\hline Escorial I.i.8 y I.i.6 & $\begin{array}{l}\text { panno uermeio } \\
\text { gusaniello }\end{array}$ & $\begin{array}{l}\text { nief } \\
\text { lana alba }\end{array}$ \\
\hline Évora CXXV/2-3 & $\begin{array}{l}\text { yerua coçano o coco } \\
\text { bermejeub, coçano o coco }\end{array}$ & $\begin{array}{l}\text { nieue } \\
\text { lana }\end{array}$ \\
\hline Escorial I.i.4 & $\begin{array}{l}\text { grana } \\
\text { gusano }\end{array}$ & $\begin{array}{l}\text { nieue } \\
\text { lana blanca }\end{array}$ \\
\hline Escorial I.i.3 & $\begin{array}{l}\text { bermejos } \\
\text { escarlata }\end{array}$ & $\begin{array}{l}\text { nieue } \\
\text { lana }\end{array}$ \\
\hline Biblia de Alba & $\begin{array}{l}\text { bermeios } \\
\text { grana }\end{array}$ & $\begin{array}{l}\text { nieue } \\
\text { lana blanca }\end{array}$ \\
\hline BN 10288 & $\begin{array}{l}\text { cremesi } \\
\text { grana }\end{array}$ & $\begin{array}{l}\text { nieue } \\
\text { lana }\end{array}$ \\
\hline RAH 87 & $\begin{array}{l}\text { paños bermejos } \\
\text { gusano }\end{array}$ & $\begin{array}{l}\text { nieue } \\
\text { lana }\end{array}$ \\
\hline
\end{tabular}

\section{LA EXCEPCIÓN: NEGRO VS. BLANCO EN IS 1, 18}

La donación de la villa de Grañeras al monasterio de Sahagún el 11 de mayo de 971 es uno de los diplomas más conocidos del rey Ramiro III de León y su tía Elvira: se conserva en pieza singular (posiblemente pseudooriginal) en una de las carpetas de pergaminos de la sección de Clero del Archivo Histórico Nacional (Madrid) y copia en el Becerro de Sahagún. El largo preámbulo doctrinal de este privilegio ensarta una serie de citas bíblicas, entre las que se encuentra precisamente el pasaje que aquí nos ocupa, Is 1, 18, pero con la llamativa particularidad de que aquí la oposición original y tradicional entre rojo y blanco se ha transformado en otra alternativa, negro versus blanco: Si fuerint peccata vestra nigriora plus quam fenicium, ego Dominus ut nivem dealbabor eam ${ }^{32}$.

\footnotetext{
${ }^{31}$ Sobre algunos de estos términos de colorantes, se pueden consultar vocabularios castellanos bajomedievales, como el Vocabulario eclesiástico de Rodrigo Fernández de Santaella (de 1499), ed. Lozano 1992: § 79, "la grana que en latín se dize granum o el color bermejo que también se dize vermiculus y hazese de la grana, que nasce en la coscoja y es como sangre muy pura". RAE, CORDE <http://corpus.rae.es/cordenet.html> [24/04/2019]

${ }^{32}$ Mínguez 1976, p. 312 (doc. n. ${ }^{\circ} 261$ ).
} 
Según Manuel Lucas ${ }^{33}$, el escribano que suscribe el documento ( $I u$ lianus confesor ${ }^{34}$ ) pertenecía a la comunidad de Sahagún, lo que, conociendo la gran prevalencia en la época de la preparación de diplomas regios a cargo de las instituciones beneficiarias, hace verosímil que se trate de una pieza redactada en el mismo monasterio. Pero la lección peculiar de Is 1, 18 no es una innovación introducida en el scriptorium de Sahagún, sino que también se encuentra en el célebre Antifonario visigótico de la catedral de León ${ }^{35}$. Concretamente, Is 1,18 se cita dos veces en este antifonario, y conforme a dos tradiciones diferentes.

En el f. 114v, aparece como en la Vulgata: Si fuerint peccata vestra ut coccinum, quasi nix dealbabuntur; et si fuerint rubra quasi vermiculus, velut lana munda erunt ${ }^{36}$.

Pero en el f. 115v, reza: Si fuerint peccata vestra nigriora plus quam fenicium, ego vero ut nivem dealbabo eam ${ }^{37}$.

Que es casi exactamente la lección del diploma de Ramiro III. La fecha de este diploma, 971, es próxima al fallecimiento del obispo Ikila de León, supuesto primer propietario del códice del Antifonario, por lo que no es en principio descartable una influencia directa. Por otra parte, es interesante que coexistan en la misma obra la lección de la Vulgata (en el f. 114v) y esta otra del f. 115v, "la del fenicio", relacionada con la tradición africana (o europea) de la Vetus Latina.

Pero lo más curioso del asunto es que la introducción del adjetivo de color en grado comparativo nigriora (referido a los pecados) no procede de la VL, por lo que cabe que pueda haber sido un añadido debido al supuesto original visigodo de época de Wamba (de 672, según se afirma en el f. 25r del Antifonario) o en otro momento posterior, hasta la confección del manuscrito a cargo del monje Totmundo o Teomundo, representado en miniatura del f. 1v haciendo entrega de su trabajo al comitente, el abad Ikila, luego obispo de León ${ }^{38}$. Más negros que el fenicio, dice. Oponer aquí el negro al blanco puede verse como avanzadilla de una tendencia que en Occidente está llamada a imponerse con el tiempo, y cuya fuerza se demuestra por haber conseguido que el redactor o copista se haya desviado de la tradición unánime de contraposición entre rojo y blanco en Is 1, 18 a la que en una sección anterior de nuestro estudio hemos pasado revista. El fenómeno es tanto más llamativo,

\footnotetext{
${ }^{33}$ Lucas Álvarez 1995, p. 225.

${ }^{34}$ Mínguez 1976, p. 313.

${ }^{35}$ Brou 1954.

${ }^{36}$ Brou, Vives 1959, p. 165

${ }^{37}$ Ibidem, p. 168.

${ }^{38}$ Yarza 1976, pp. 186-189.
} 
cuanto que el escriba no parece haber advertido la patente incoherencia con la glosa marginal presente en el mismo folio del Antifonario (y que él mismo debe de haber copiado), tomada de las Etimologías de san Isidoro de Sevilla, en la que se explica el sentido del término fenicio aplicado a un color: pigmento sirio de color rojo, con que se escriben las letras de capítulo en los libros ${ }^{39}$. Que en el texto principal, contrariando toda tradición, se contraponga el color negro al blanco, y más todavía, que el negro aparezca asociado al término fenicio en lugar del rojo (que desde la Antigüedad ha dado nombre a este pueblo y ha sido el color fenicio por excelencia), constituye tal vez un lapsus revelador del escriba, una suerte de fenómeno inconsciente, indicativo de un cambio de mentalidad in fieri, ahora que el rojo va dejando de percibirse como el contrario natural del blanco, para ser reemplazado por el negro.

Por dejar en este punto más clara nuestra hipótesis, creemos que el comparativo nigriora del pasaje no es verosímil que proceda de la liturgia hispana o visigótica, ya que contradice no solamente el texto bíblico de la Vetus Latina y de la Vulgata, sino incluso directamente, en la glosa marginal, la enciclopedia isidoriana. Estimamos, así, necesario atribuirlo a un momento posterior, tal vez al mismo en que el códice del Antifonario fue copiado, posiblemente con anterioridad a 971, fecha del diploma de Ramiro III que parece estar citándolo.

\section{BLANCO, NEGRO Y ROJO: SUS VALORES Y TÉRMINOS DE OPOSICIÓN}

En términos antropológicos generales, resulta claro que el blanco, el negro y el rojo son los tres colores más universalmente reconocidos y más significativos (esto es, cargados de elementos de sentido en muchos niveles) ${ }^{40}$. En un estudio ya clásico ${ }^{41}$, Brent Berlin y Paul Kay estudiaron el léxico de color de un centenar de lenguas, y llegaron a la conclusión de que en todas hay una palabra para el blanco y otra para el negro; si hay un tercer término de color, siempre es el rojo; el resto de colores principales ocupan posiciones menos destacadas en esta secuencia que ellos estimaron como definitoria de un patrón evolutivo universal, lo que posteriormente se ha sometido a críti-

\footnotetext{
${ }^{39}$ La glosa completa (f. 115v) reza: "Fenicium appellatur eo quod in Syria colligitur in litoribus rubri maris, ubi fenices inhabitant. Ipsut est siriacum rubri coloris pigmentum, ex quo et librorum capita scribuntur": Brou, Vives 1959, p. 168. Procede de Isidoro, Etymologiae, 19, 17 (De coloribus).

${ }^{40}$ Sólo como ejemplo de una vasta bibliografía, puede consultarse MacLaury, Paramei, Dedrick 2007.

${ }^{41}$ Berlin, Kay 1969.
} 
$\mathrm{ca}^{42}$; pero no así la incontrovertible afirmación de que esos tres son los más eminentes entre todos los colores, en ese orden precisamente: blanco y negro; luego, rojo $^{43}$.

Si se examina la cuestión desde un punto de vista natural, tal vez quepa concluir que la razón de la diferencia en el lugar respectivo que se concede al blanco y al negro por un lado y al rojo por otro puede deberse al hecho de que de estos tres términos básicos, el blanco y el negro no representan propiamente matices cromáticos, sino los extremos opuestos correspondientes respectivamente a las nociones de luz y obscuridad, en tanto que el rojo es, de los tres, el único término con valor cromático propiamente, esto es, referido a un color $^{44}$. Dicho de otro modo, puede establecerse que el blanco tiene dos opuestos posibles: si se entiende el blanco como representación de la máxima luminosidad, su opuesto es el negro, que encarna la máxima obscuridad ${ }^{45}$; y si se concibe el blanco como ausencia de tonalidad cromática o "limpieza", el rojo vendría a ser su contrario como "tinte" por excelencia y en términos de saturación. Tal es el esquema básico de tipo ternario, que la Edad Media hereda de la Antigüedad ${ }^{46}$, y que Michel Pastoureau explica como apoyado sobre una doble oposición: "de valor" (blanco-negro) y "de densidad" (blanco-rojo) ${ }^{47}$.

\begin{tabular}{|l|l|l|}
\hline NEGRO & BLANCO & ROJO \\
\hline $\begin{array}{l}\text { obscuridad } \\
\text { acromatismo } \\
\text { insaturación }\end{array}$ & $\begin{array}{l}\text { luminosidad } \\
\text { acromatismo } \\
\text { insaturación-limpieza }\end{array}$ & $\begin{array}{l}\text { cromatismo } \\
\text { saturación-tinción }\end{array}$ \\
\hline
\end{tabular}

De esta caracterización general de los tres colores principales en términos de oposición cabe derivar múltiples consecuencias de todo orden en la esfera del simbolismo y la mentalidad (por ejemplo, la definición en términos de colores de las clases o funciones sociales en los pueblos de raíz indoeuropea ${ }^{48}$ ). Pero para apreciar matices y líneas de evolución pertinentes al fenómeno al que nos aproximamos en este trabajo, es de interés entrar a revisar algunos ejemplos de empleo de estos términos de color en algunos hitos dentro de la tradición de la literatura occidental.

${ }^{42}$ Conklin 1973; Saunders 2000.

${ }^{43}$ Taçon 1999, p. 120.

${ }^{44}$ Pastoureau 2016, p. 14.

${ }^{45}$ Crone 1999

${ }^{46}$ Sobre el mundo cromático medieval existe una amplísima bibliografía; véase, como muestra: Bennewitz, Schindler 2011.

${ }^{47}$ Pastoureau 1986, pp. 44-45.

${ }^{48}$ Benveniste 1969 , p. 279. 


\section{BLANCO, NEGRO Y ROJO: EJEMPLOS EN LA MENTALIDAD Y LA LITERATURA}

El primer fundamento y la primera referencia -no únicamente en términos cronológicos de antigüedad- que entra a formar el mundo mental y literario medieval es sin duda el texto bíblico, cuya omnipresencia se descubre actuando en toda suerte de manifestaciones culturales ${ }^{49}$. La utilización de estos tres colores básicos por los que aquí nos interesamos reviste en las Escrituras un rico simbolismo, cuyos valores han de pasar al fondo común de la Cristiandad medieval.

En la Biblia, el blanco se asocia con frecuencia a las vestiduras: así, por ejemplo, en Sal $51,9^{50}$ se relaciona con la limpieza, inocencia y purificación (como en Is 1, 18); en Ecl 9, $8^{51}$ se asocia a la alegría y disfrute de los dones de la vida terrenal; también sirve para caracterizar a algunos personajes simbólicos, como el anciano sentado en el trono de las revelaciones del sueño de Daniel (Dan 7, $9^{52}$ y el Verbo Divino, jinete sobre un caballo blanco, del Apocalipsis (Apoc 6, $2^{53}$ y 19, 14 $4^{54}$ ), además de adornar al mismo Cristo en Su transfiguración (Mc 9, 255; Mt 17, 256; Lc 9, 2957). Al menos una vez se emplea también con un sentido negativo, por el mismo Cristo cuando habla de los sepulcros blanqueados refiriéndose a la hipocresía de los fariseos (Mt 23, 27 $7^{58}$.

El rojo caracteriza algunos animales, como la vaca para el sacrificio en Núm 19, $2^{59}$, y algunos caballos (Zac 1, $8^{60}$; Apoc 6, $4^{61}$ ) o el dragón del

\footnotetext{
49 "Il suffit de parcourir, du VIII' au X $\mathrm{X}^{\mathrm{e}}$ siècle, les écrits les plus divers, traités de bon gouvernement, lettres, descriptions des cérémonies liturgiques, pour être frappé de la fréquence des citations bibliques": David 1951,p. 24.

50 "lavabis me, et super nivem dealbabor".

51 "Omni tempore sint vestimenta tua candida, et oleum de capite tuo non deficiat".

52 "Aspiciebam donect throni positi sunt, et antiquus dierum sedit. Vestimentum eius candidum quasi nix, et capilli capitis eius quasi lana munda".

53 "Et vidi, et ecce equus albus, et qui sedebat super illum habebat arcum, et data est ei corona, et exivit vincens ut vinceret".

${ }^{54}$ "Et exercitus qui sunt in caelo, sequebantur eum in equis albis, vestiti byssino albo et mundo".

55 "Et vestimenta eius facta sunt splendentia, et candida nimis velut nix, qualia fullo non potest super terram candida facere".

56 "et transfiguratus est ante eos. Et resplenduit facies eius sicut sol; vestimenta autem eius facta sunt alba sicut nix".

57 "Et facta est, dum oraret, species vultus eius altera, et vestitus eius albus et refulgens".

58 "Vae vobis scribae et pharisaei hypocritae, quia similes estis sepulchris dealbatis".

59 "Praecipe filiis Israel ut adducant ad te vaccam rufam aetatis integrae in qua nulla sit macula, nec portaverit iugum".

60 "Vidi per noctem, et ecce vir ascendens super equum rufum, et ipse stabat inter myrteta, quae erant in profundo, et post eum equi rufi, varii, et albi".

61 "Et exivit alius equus rufus: et qui sedebat super illum, datum est ei ut sumeret pacem de terra, et ut invicem se interficiant, et datus est ei gladius magnus".
} 
Apocalipsis (Apoc 12, $3^{62}$ ). Se combina en ocasiones con los otros colores básicos, como en el pasaje de Zacarías donde se habla de los cuatro vientos del cielo (caballos rojos, negros, blancos y de colores mezclados: Zac 6, $2^{63}$ ); y muy especialmente, se combina el rojo con el blanco, como en el anciano del sueño de Daniel antes citado (Dan 7,9), cuyas vestiduras son blancas como la nieve y cabellos como lana limpia, pero sedente en un trono de llama de fuego ${ }^{64}$, términos y oposición retomados casi verbatim en el Apocalipsis (Apoc 1,1455). También hay un jinete en el Apocalipsis sobre un caballo negro (Apoc 6, $5^{66}$ ), pero el simbolismo del negro no parece que tenga tanto desarrollo en las Escrituras: sin especial intención se habla en la obra de los seis días de la creación de ganado caprino negro (Gen 30, 35 $5^{67}$ ), de gentes de tez obscura "como el negro de olla" (Nah 2, $10^{68}$ ), y de que no está en nuestra mano hacer que sean blancos o negros los cabellos de nuestra cabeza (Mt 5, $\left.36^{69}\right)$.

No es éste, por lo demás, el lugar más adecuado para proceder a una revisión de conjunto de la evolución de estas concepciones con fundamento bíblico en la literatura del Occidente medieval ${ }^{70}$. Nos contentaremos aquí con centrarnos en unos pocos ejemplos, escogidos como hitos de dicha evolución, con particular atención al ámbito hispánico. En el Setenario, por ejemplo, se asocia el color rojo a Cristo, por la Pasión (§ 52), y también se compara con Marte (cuyo color es el rojo desde la Antigüedad) al mismo Cristo y al Espíritu Santo $(\$ \S 52,67,69)$; por el contrario, en la misma obra el negro representa a Saturno, asemejado a Dios Padre $(\S \S 32,54)^{71}$. En uno de los cuentos del

\footnotetext{
62 "Et visum est aliud signum in caelo: et ecce draco magnus rufus habens capita septem et cornua decem".

63 "In quadriga prima equi rufi, et in quadriga secunda equi nigri, et in quadriga tertia equi albi, et in quadriga quarta equi varii et fortes".

64 "Vestimentum eius candidum quasi nix, et capilli capitis eius quasi lana munda; thronus eius flammae ignis, rotae eius ignis accensus".

65 "caput autem eius et capilli erant candidi tamquam lana alba et tamquam nix, et oculi eius tamquam flamma ignis".

66 "Et ecce equus niger, et qui sedebat super illum habebat stateram in manu sua".

67 "Et separavit in die illa capras, et oves, et hircos, et arietes varios, atque maculosos: cunctum autem gregem unicolorem, id est albi et nigri velleris".

68 "et facies omnium eorum sicut nigredo ollae".

69 "neque per caput tuum iuraveris, quia non potes unum capillum album facere, aut nigrum".

${ }^{70}$ Algunas referencias sobre la formación del sistema cromático medieval y, por vía de ejemplo, su plasmación litúrgica, en Aoiz 2015, pp. 128-147, 187-195.

${ }^{71}$ Vanderford 1945: "Et de los metales le dauan [a Saturno] el plomo porque es negro e [...] de las piedras, toda piedra dura e negra" (§ 32, p. 63); "Et por ende Ihesu Cristo ffue Mars tan bien en el nonbre commo en la obra de uençer. Et la color que dauan a Mars de fazion e de armaduras era toda bermeia. Et era a ssemeiante de la ssangre de Ihesu Cristo que ffue todo cubierto por nos" (§ 52, p. 86); "Et estas uestiduras negras quel dauan [a Saturno], esto es assi
} 
Calila e Dimna un rey se ve en sueños sobre un monte blanco, con el cuerpo cubierto de sangre y lavado luego con agua ${ }^{72}$; la mezcla de la sangre y el agua remite al contexto simbólico de las ceremonias de purificación como aquellas a las que nos hemos referido a propósito de Is 1,18 y su tradición ${ }^{73}$.

Concretamente, hay numerosas instancias en el acervo literario medieval de empleo simbólico de oposición blanco-rojo, con una gran fuerza poética y de significación, como por ejemplo en el famoso pasaje del Cuento del Grial de Chrétien de Troyes donde el héroe halla un rastro de sangre sobre la nieve y el efecto de contraste despierta en él una intensa evocación de Blancaflor ${ }^{74}$. Según precisa Michel Pastoureau, para la sensibilidad medieval no existía contraste de color más significativo que el blanco-rojo, pues estos colores se consideraban entonces en absoluto los más antitéticos, tanto en el plano material como simbólico ${ }^{75}$.

Sin embargo, el mismo autor postula en la evolución del gusto y de la mentalidad un cambio relevante que en Occidente sitúa como acontecido posteriormente al año 1000, y este cambio (el mismo que en nuestro presente estudio pretendemos documentar con el ejemplo de la traducción de Is 1, 18) entiende poderlo ilustrar con la historia de la aclimatación occidental del juego del ajedrez. En efecto, cuando el ajedrez nace, posiblemente hacia el siglo VI a. C. en el norte de la India, los dos colores que opone (en sus fichas y tablero) son el negro y el rojo que en Asia conforman el contraste más típico y significativo, por considerarse cada uno la antítesis del otro; y en este formato se difunde el ajedrez por el mundo islámico. Pero, cuando este juego llega al Occidente europeo, poco antes del año 1000, se cambia el negro por blanco, y la oposición pasa a ser blancas contra rojas: ello debido a que para la mentalidad occidental el rojo y el negro no representan opuestos, sino que más bien son dos colores sin relación alguna entre sí, tanto menos de oposición ${ }^{76}$.

En Occidente, el cambio fundamental de mentalidad que permite pasar de blanco-rojo a blanco-negro como la oposición más significativa se

commo el color negro es oscuro que çierra el viso, assi a Dios ninguno non puede uer en este mundo en la deidat ssinon por Ihesu Cristo ssu ffijo" ( $\$ 54$, p. 90); "La terçera planeta, que llaman, Mars, esta sse entiende por el Spiritu Ssanto, que es todo bermeio a ssemejante del ffuego que ssale del Padre e del Ffijo e ençiende las uoluntades de los omnes en amor de Dios" (§ 67, p. 114; variante en nota); "Et por la color de la cara bermeia [...] sse entiende el Spiritu Ssanto" (\$ 69, p. 117).

${ }^{72}$ Gayangos 1860, p. 60.

${ }^{73}$ También, por ejemplo, en el Apocalipsis, donde se habla de lavar o blanquear en la sangre del Cordero: "Hi sunt, qui venerunt de tribulatione magna, et laverunt stolas suas, et dealbaverunt eas in sanguine Agni" (Apoc. 7, 14).

${ }^{74}$ Chrétien de Troyes, 1970, versos 4109 y ss. Sobre el alcance y significación de esta imagen: Rey-Flaud 1980; Poirion 1998.

${ }^{75}$ Pastoureau 2016, pp. 85, 100.

${ }^{76}$ Ibidem, pp. 99-100. 
produce posiblemente al hilo de la recuperación por la escolástica del legado aristotélico en su integridad. En efecto, la difusión del breve tratado de Aristóteles sobre los colores, donde viene a afirmar que el blanco y el negro constituyen los dos colores extremos y opuestos ${ }^{77}$, provocará ese cambio de mentalidad de acuerdo con el cual la oposición blanco-negro pasará a considerarse como más evidente y llena de sentido que la anterior y tradicional, blanco-rojo. Así, por ejemplo, autores con fondo aristotélico como santo Tomás de Aquino darán por sabido que el negro es el contrario del blanco, de lo que pueden hallarse numerosos ejemplos en sus obras ${ }^{78}$, y contribuirán a apuntalar en la cultura de la época este cambio de percepción.

En esta época que podríamos llamar "postaristotélica" de la cultura del Occidente medieval, el blanco y el negro pasarán a estar presentes en numerosos escritos, en términos de oposición ${ }^{79}$ : en el libro de los Castigos de Sancho IV se asigna al blanco valores positivos, asociados a la limpieza y pureza (la virtud del rey y la castidad de los prelados) y se contrapone con el negro (por ejemplo, al separar la mesura de la desmesura, como lo blanco de lo negro ${ }^{80}$. En el Libro de los enxemplos, el blanco se identifica con el bien y el negro con el mal: así, en relación con una mujer negra, personificación de la lujuria; con los ángeles malos en forma de estrellas negras; y con la virtud que la oración tiene de transformar lo negro en blanco ${ }^{81}$. El Arcipreste de Hita, para justificar la forma vil de su famoso libro por un con-

${ }^{77}$ Crone 1999, p. 11.

${ }^{78}$ Tomás de Aquino, Summa theologiae: I, q. 67, a. 3 (toda cualidad sensible tiene su contrario, como lo blanco de lo negro); I, q. 77, a. 3 y I, q. 81, a. 2 (la potencia de visión es idéntica para lo blanco y para lo negro); I-II, q. 35, a. 4 (la delectación y la tristeza se oponen universalmente, como cualidades contrarias, de la misma forma que lo blanco y lo negro); II-II, q. 4, a. 8 y II-II, q. 26, a. 7 (es más blanco lo que tiene menos de negro); II-II, q. 79, a. 4 (un contrario dista más de su contrario que su simple negación, como lo negro dista más de lo blanco que de lo simplemente no blanco); III, q. 75, a. 4 (por ser radicalmente opuestos, lo blanco nunca se transforma en negro); III, q. 85, a. 3 (cualquier virtud excluye el hábito del vicio opuesto, de la misma manera que lo blanco excluye lo negro en el mismo sujeto).

${ }^{79}$ Nogales 2016, p. 227, nota 26.

${ }^{80}$ Castigos de Sancho IV, en Gayangos 1860: "el rey, como el paño blanco en que no ha mancilla ninguna" (p. 98); "La forradura deste rey eran peñas blancas armiñas, por la cual se demuestra la limpieza que el rey debe haber en la su alma" (p. 111); "Mio fijo: tal es la mesura en el rey e asi paresce de lejos, como la torre muy alta, blanca e bien labrada que divisan los homes muy lejos" (p. 117); "En la mesura verás muchos de bienes e muchas bondades. En la desmesura verás muchas de maldades, e asi es departida la una de la otra, como es departido lo blanco de lo prieto" (p. 118); "Tal es la virginidat e la castidat en el buen perlado, como el paño blanco en que non ha mancilla ninguna" (p. 163).

${ }^{81}$ Libro de los enxemplos, en Gayangos 1860: "aparescióle una mujer muy negra e muy fea, legañosa, e toda sarnosa, do salie aquel fedor" (p. 478); "Dicen que un monje (...) habie tal gracia e tal don de Dios, que veie sobre cada homme justo e malo un angel malo en figura de estrella negra" (p. 479); "E asi parat mientes que la oracion face de lo negro blanco, e de lo oscuro claro, e del cruel piadoso, e del siervo del diablo siervo de Dios" (p. 512). 
tenido de valor, recurre al ejemplo de cosas negras que contienen blanco en su interior ${ }^{82}$; cuando más adelante canta las alabanzas del amor, indica que éste provoca transformaciones de cualidades en sus opuestas, como el paso de negro a blanco ${ }^{83}$; tanto aquí, como en el ejemplo del pavón y la corneja, identifica la belleza con lo blanco y la fealdad con lo negro ${ }^{84}$; como también, al caracterizar como negras las partes corporales de una de las serranas para retratarla como fea ${ }^{85}$; asimismo, en este Libro de buen amor, se establece una correspondencia o paralelismo de las almas blancas con las fermosas y de las prietas con las feas ${ }^{86}$.

Concluyendo su ejemplo del ajedrez, Pastoureau indica que, cuando desde mediados del siglo XIV, en un contexto de cambio de mentalidad vinculado con esta concepción aristotélica del blanco y el negro como los dos colores extremos, ya su oposición se considera en Occidente como más significativa y actual que la de blanco frente al rojo, el ajedrez pasa a jugarse sobre un tablero blanco y negro, con fichas de estos colores ${ }^{87}$. Este cambio de mentalidad y de percepción define, a nuestro juicio, el contexto preciso en que hemos pretendido explicar las razones profundas de la traducción errónea del tinte fenicio (rojo) como negro, en el referido pasaje de Is 1,18 , como un fenómeno que sólo en las coordenadas de dicho cambio deviene culturalmente posible y provisto de sentido.

\section{CONCLUSIÓN}

En el presente trabajo hemos querido analizar una instancia concreta llamativa que, en nuestra opinión, viene a ilustrar un interesante cambio de mentalidad, ya postulado en términos más generales, a cuenta del paso del rojo al negro como el color opuesto al blanco por excelencia.

Según nuestra interpretación, la introducción de la expresión nigrio$r a$ (atribuida a los pecados y que se refiere al colorante fenicio como término de comparación) en una cita parcial de Is 1,18 constituye un error del escri-

\footnotetext{
${ }^{82}$ Arcipreste de Hita, Libro de buen amor: "ansí en feo libro esta saber non feo. / El axenus de fuera mas negro es que caldera, / es de dentro muy blanco, mas que la pennavera, / blanca farina esta so negra cobertera" (16d y 17a-c).

${ }^{83}$ Ibidem: "[el amor] faze blanco e fermoso del negro como pez" (157c).

${ }^{84}$ Ibidem: "la negra por ser blanca contra si se denueda" (285d).

${ }^{85}$ Ibidem: "cabellos muy negros, mas que cornexa lisa" (1012b); "el su pescueço negro, ancho, velloso, chico" (1013b); "las sobrecejas anchas e mas negras que tordos" (1014c); "custillas mucho grandes en su negro costado" (1020a).

${ }^{86}$ Ibidem: "Vengan [almas] fermosas o feas, quier blancas, quier prietas" (386b).

${ }^{87}$ Pastoureau 2016, p. 202; 2012, pp. 30-34.
} 
ba o copista del Antifonario visigótico de León, y no creemos que se pueda asignar a la liturgia hispana que en dicho Antifonario se refleja, ya que tal expresión no pertenece a ninguna tradición del pasaje referido de Is 1,18 , ni de la Vetus Latina ni de la Vulgata (antes bien, entra en contradicción no sólo con ella, donde unánimemente se contrapone el rojo al blanco, sino con la cita aclaratoria sobre el colorante fenicio extraída de las Etimologías isidorianas, copiada en el mismo folio del Antifonario).

Ahora bien, también consideramos dicho lapsus como no casual ni inocente, sino freudianamente revelador como indicio de un cambio de mentalidad que, según Michel Pastoureau se opera en la cultura occidental sobre todo a partir del año 1000, pasando de la contraposición de color básica blanco-rojo a la alternativa blanco-negro, que se consolidará como la más significativa hasta nuestro propio tiempo. Precisamente, por ser la aparición del nigriora que analizamos, tanto en el diploma visto de Ramiro III como en el texto del Antifonario de León, anterior (aunque no mucho) al año 1000, estimamos que constituye una instancia de alguna importancia e interés, no sólo porque indirectamente ayudaría a fechar el Antifonario, sino sobre todo porque se anticipa como una suerte de avanzadilla a una tendencia que con el paso del tiempo irá ganando fuerza y llevará posteriormente, en el contexto de la cultura occidental impregnada de aristotelismo escolástico, a manifestaciones tan explícitas como las evocadas en nuestro estudio, y a redefiniciones tan interesantes como la modificación definitiva de los colores del juego de ajedrez.

\section{BIBLIOGRAFÍA CITADA}

Aoiz Orduna, Javier (2015), Color / No-color: los blancos en la cultura occidental, Madrid, Universidad Complutense (tesis doctoral).

Arcipreste de Hita (1974), Libro de buen amor, ed. J. Joset, Madrid, EspasaCalpe.

Asurmendi, Jesús M. (1981), Isaías 1-39, Estella, Verbo Divino.

Bennewitz, Ingrid; Schindler, Andrea (eds.) (2011), Farbe im Mittelalter. Materialität, Medialität, Semantik, Berlín, Akademie.

Benveniste, Émile (1969), Le vocabulaire des intitutions indo-européennes. I. Économie, parenté, société, París, Les Éditions de Minuit.

Berlin, Brent; Kay, Paul (1969), Basic Color Terms: Their Universality and Evolution, Berkeley, University of California Press.

Blenkinsopp, Joseph (2015), El libro de Isaías. 1-39, Salamanca, Sígueme.

Brou, Louis (1954), Le joyau des antiphonaires latins: le manuscrit 8 des Archives de la Cathédrale de León, "Archivos leoneses" 8/5, pp. 7-114. 
Brou, Louis; Vives, José (eds.) (1959), Antifonario visigótico mozárabe de la catedral de León, Barcelona - Madrid, Instituto P. Enrique Flórez.

Carr, David M. (1996), Reading Isaiah from Beginning (Isaiah 1) to End (Isaiah 65-66): Multiple Modern Possibilities, en Melugin, Roy F.; Sweeney, Marvin A. (eds.), New Visions of Isaiah, Mansion House, Sheffield Academic Press, pp. 188-218.

Chrétien de Troyes, Le Conte du Graal, ed. F. Lecoy, París, Honoré Champion, 1970 .

Conklin, Harold C. (1973), Color Categorization, "The American Anthropologist" 75/4, pp. 931-942.

Crone, Robert A. (1999), A History of Color. The Evolution of Theories of Lights and Color, Dordrecht, Kluwer Academic.

David, Marcel (1951), Le serment du sacre du IXe au XV siècle, Estrasburgo, Palais de l'Université.

Enrique-Arias, Andrés (dir.), Biblia medieval, http://www.bibliamedieval.es [consulta: 01/04/2019].

Gayangos, Pascual de (1860), Escritores en prosa anteriores al siglo XV, Madrid, Rivadeneyra.

Goldingay, John (1981), If Your Sins Are Like Scarlet ...(Isaiah 1:18), "Studia Theologica" 35, pp. 137-144.

Gryson, Roger (1987), Vetus Latina. Die Reste der Altlateinischen Bibel. 12. Esaias. 1, Friburgo de Brisgovia, Herder.

Kutsch, Ernst (1982), Wir wollen miteinander rechten: zu Form und Aussage von Jes. 1, 18-20, en Ruppert, Lothar; Weimar, Peter; Zenger, Erich (eds.), Künder des Wortes. Festschrift für Josef Schreiner, Wurzburgo, Echter Verlag, pp. 23-33.

Lozano, Gracia (ed.) (1992), Vocabulario eclesiástico de Rodrigo Fernández de Santaella, Madison, Hispanic Seminary of Medieval Studies.

Lucas Álvarez, Manuel (1995), El reino de León en la Alta Edad Media. VIII. La documentación real astur-leonesa (718-1072), León, Centro de Estudios "San Isidoro".

MacLaury, Robert E.; Paramei, Galina V.; Dedrick, Don (eds.) (2007), Anthropology of Color. Interdisciplinary Multilevel Modeling, Amsterdam - Filadelfia, John Benjamins.

Melugin, Roy F. (1996), Figurative Speech and the Reading of Isaiah 1 as Scripture, en Melugin, Roy F.; Sweeney, Marvin A. (eds.), New Visions of Isaiah, Mansion House, Sheffield Academic Press, pp. 282305.

Mínguez Fernández, José María (1976), Colección diplomática del monasterio de Sahagún. I (siglos IX y X), León, Centro de Estudios "San Isidoro". 
Nogales Rincón, David (2016), El color negro: luto y magnificencia en la Corona de Castilla (siglos XIII-XV), "Medievalismo" 26, pp. 221-245.

Pastoureau, Michel (1986), Figures et couleurs. Études sur la symbolique et la sensibilité médiévales, París, Le Léopard d'Or.

Pastoureau, Michel (2012), Le jeu d'échecs médiéval. Une histoire symbolique, París, Le Léopard d'Or.

Pastoureau, Michel (2016), Rosso, Milán, Adriano Salani.

Phipps, Elena (2010), Cochineal Red.The Art History of a Color, Nueva York New Haven - Londres, The Metropolitan Museum of Art - Yale University Press.

Plinio el Viejo, Historia natural. Libros VII-XI, trad. y notas de E. del Barrio Sanz, I. García Arribas, A. M. ${ }^{a}$ Moure Casas, L. A. Hernández Miguel, M. ${ }^{a}$ L. Arribas Hernáez, Madrid, Gredos, 2003.

Poirion, Daniel (1998), Du sang sur la neige. Nature et fonction de l'image dans Le Conte du Graal, en Hüe, Denis (ed.), Polyphonie du Graal, Orleans, Paradigme, pp. 99-112.

Rey-Flaud, Henri (1980), Le sang sur la neige. Analyse d'une image-écran de Chrétien de Troyes, "Littérature" 37, pp. 15-24.

Sagrada Biblia. Versión oficial de la Conferencia Episcopal Española (2011), Madrid, Biblioteca de Autores Cristianos.

Saunders, Barbara (2000), Revisiting Basic Color Terms, "Journal of the Royal Anthropological Institute" 6, pp. 81-99.

Sweeney, Marvin A. (1996), Isaiah 1-39 with an Introduction to Prophetic Literature, Grand Rapids (Michigan) - Cambridge, William B. Eerdmans Publishing Company.

Tábet, Miguel Ángel; Marconcini, Benito; Boggio, Giovanni (2008), Introducción al Antiguo Testamento. II. Libros proféticos, Madrid, Palabra.

Taçon, Paul S. C. (1999), All Things Bright and Beautiful: The Role and Meaning of Colour in Human Development, "Cambridge Archaeological Journal" 9, pp. 120-126.

Tatarkiewicz, Wladyslaw (1989), Historia de la estética. II. La estética medieval, Madrid, Akal.

Tomás de Aquino, Suma de teología, ed. J. Martorell, Á. Martínez, G. Cela-

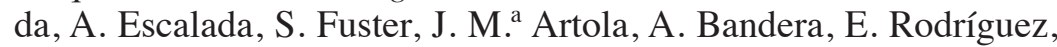
F. Soria, Madrid, Biblioteca de Autores Cristianos, 2001 [= 1994²].

Troxel, Ronald L. (2008), LXX-Isaiah as Translation and Interpretation. The Strategies of the Translator of the Septuagint of Isaiah, Leiden - Boston, Brill.

Vanderford, Kenneth H. (ed.) (1945), Setenario, Buenos Aires, Universidad. 
Vaux, Roland de (1976), Instituciones del Antiguo Testamento, Barcelona, Herder.

Willis, John T. (1983), On the Interpretation of Isaiah 1:18, "Journal for the Study of the Old Testament" 25, pp. 35-54.

Yarza Luaces, Joaquín (1976), Las miniaturas del Antifonario de León, "Boletín del Seminario de Estudios de Arte y Arqueología" 42, pp. 181-210.

Fecha de recepción del artículo: abril 2019

Fecha de aceptación y versión final: enero 2020 